\title{
Estimation of Wind Direction in Tropical Cyclones Using C- Band Dual-Polarization Synthetic Aperture Radar
}

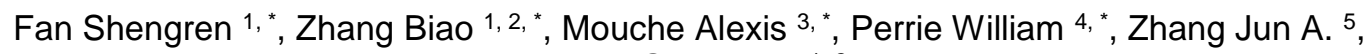 \\ Zhang Guosheng ${ }^{1,2}$
}

\begin{abstract}
1 Nanjing Univ Informat Sci \& Technol, Sch Marine Sci, Nanjing 210044, Peoples R China.
2 Southern Marine Sci \& Engn Guangdong Lab, Zhuhai 519082, Peoples R China.

3 Inst Francais Rech Exploitat Mer, Lab Oceanog Phys Spatiale, F-29280 Plouzane, France.

${ }^{4}$ Fisheries \& Oceans Canada, Bedford Inst Oceanog, Dartmouth, NS B2Y 4A2, Canada.

5 Univ Miami, Hurricane Res Div, NOAA, Atlantic Oceanog \& Meteorol Lab,Cooperat Inst Mar, Miami, FL 33149 USA.
\end{abstract}

Corresponding authors : email addresses : sr fan@nuist.edu.cn ; zhangbiao@nuist.edu.cn ; alexis.mouche@ifremer.fr ; william.perrie@dfo-mpo.gc.ca

\begin{abstract}
:
Under extreme weather conditions, the imprints of kilometer-scale marine atmospheric boundary layer roll vortices on the ocean surface are clearly visible in synthetic aperture radar (SAR) images of storms. Therefore, information about wind direction in storms can be obtained by analyzing SAR image features caused by boundary layer rolls. VH-polarized SAR imagery captures the structural features of storms well and shows prominent image gradients along the radial directions of the storm. The signal-to-noise ratios of $\mathrm{VH}$-polarized images are small in low wind speed areas, but they are large in the same regions of $\mathrm{VV}$ polarized images. Also, the capability of retrieving the atmospheric rolls orientation in VV-polarization is found to be sensitive to incidence angle, with better performances for larger incidence angles. Thus, there is the potential to retrieve the storm's wind directions using a combination of the VH- and VV-polarized SAR observations. In this article, we use the local gradient method to estimate tropical cyclone (TC) wind directions from C-band RADARSAT-2 and Sentinel-1A dual-polarization (VV \& x002B; VH) SAR imagery. As a case study, wind directions with a spatial resolution of $25 \mathrm{~km}$ are derived by using both wide-swath VV- and VH-polarized SAR imagery over two hurricanes (Earl and Bertha) and one Typhoon (Meranti). We compare wind directions derived from ten dual-polarization SAR images with collocated wind directions from buoys, Global Positioning System (GPS) dropsondes, scatterometer, and radiometer. Statistical comparisons show that the wind direction bias and root-mean-square error are, respectively, $0.54 \& \mathrm{x} 00 \mathrm{~B} 0$; and 14.78 \& x00B0; for VV-polarization, 0.38 \& x00B0; and $14.25 \& \times 00 \mathrm{~B} 0$; for $\mathrm{VH}-$ polarization, 0.20 \& x00B0; and $13.30 \& \times 00 \mathrm{~B} 0$; for $\mathrm{VV}$ - and $\mathrm{VH}$-polarization, suggesting dual-polarization SAR is more suitable for the estimation of TC wind directions than VV- or VH-polarization SAR.
\end{abstract}

Keywords: Synthetic aperture radar, Radar polarimetry, Wind speed, Atmospheric modeling, Spaceborne radar, Radar measurements, Synthetic aperture radar (SAR), tropical cyclone (TC), wind direction 


\section{INTRODUCTION}

TN ORDER to better understand the tropical cyclone (TC) intensity and to track wind field structure evolution, there is a need for a continuous monitoring of TCs. Due to its high spatial resolution, wide-swath acquisitions, and its capability to operate at day and night, C-band spaceborne synthetic aperture radar (SAR) microwave sensors have proven to be very promising. Moreover, C-band SARs operate at low frequency $(\sim 5.3 \mathrm{GHz})$; therefore, SAR signals are not severely impacted by rain and cloud, even when observing TCs [1]. Over the last decade, a great deal of effort has been devoted to the derivation of TC wind fields. This has been fostered by the recent opportunity to have acquisitions in both co- and cross-polarization, thanks to RADARSAT-2 and Sentinel-1 SAR missions [2]-[7].

According to the Beaufort wind scale, we consider the scale number $<6(13.8 \mathrm{~m} / \mathrm{s}), 7-9(13.9-24.4 \mathrm{~m} / \mathrm{s})$, and $>10$ $(24.5 \mathrm{~m} / \mathrm{s})$ as the low winds, moderate winds, and high winds, respectively. For low and moderate winds, co-polarization (VV or HH) SAR wind speed retrievals are based on the geophysical model functions (GMFs) derived from scatterometers. Since there are two unknown parameters (wind speed and direction) and only nonrotational antenna, the inverse problem is under-constrained. To overcome this limitation in SAR systems, the wind direction is generally set before retrieving the wind speed. In general, the numerical weather predictions from global and operational atmospheric models such as the Navy Operational Global Atmospheric Prediction System (NOGAPS) model are used to provide wind direction inputs for SAR wind speed retrievals [8]. This method tends to produce physically reasonable estimates when the time 
difference (between model output and SAR acquisition time) is lower than $1.5 \mathrm{~h}$ or when the meteorological situation is not too complex with rapidly changing systems (e.g., for atmospheric fronts or low-pressure systems). However, the spatial resolution of the weather forecast model is generally coarser $\left(0.125^{\circ}\right)$ than what is achieved for SAR (about $500 \mathrm{~m}-1 \mathrm{~km}$ ). Scatterometer wind directions are also a candidate external source for SAR wind-speed retrieval [9]. However, in coastal areas, scatterometer observations are contaminated by land backscattering and cannot provide accurate wind directions in these areas. Moreover, there will be important time intervals between SAR acquisitions and scatterometer winds for collocation. For example, the time difference is about $9 \mathrm{~h}$ between C-band RADARSAT-2 and ASCAT for observing the same region. Under TC conditions, Ku-band scatterometer signals are affected by heavy rainfall which has potential to induce significant wind retrieval error. Furthermore, both methods have the risk of possible inaccuracies in wind direction due to interpolation; when interpolating data from a weather model or scatterometer wind direction to a given SAR pixel, there may be spatial or temporal differences between the SAR data and the external source. In the case of translating and rotating phenomena such as TCs, the interpolation may become unreliable.

When we rely only on SAR images, it is sometimes possible to extract wind directions from kilometer-scale wind streaks due to marine atmospheric boundary layer (MABL) rolls [10], [11]. The direction of the wind streaks can be determined by using the fast Fourier transform (FFT) method [10], [12]-[14], the local gradient (LG) method [15], [16], or the wavelet transform (WT) method [17]. The wind directions derived from these approaches have a $180^{\circ}$ ambiguity, which can be resolved by examining the wind shadowing visible on the lee of the coastlines, or by other wind sources such as atmospheric numerical models or in situ measurements [13], [14]. A previous study reported that the FFT method determines the wind direction with a rootmean-square error (RMSE) of $\pm 24^{\circ}$ when compared to in situ wind measurements [12]. The wind directions derived from the LG method were also compared with those from a numerical weather forecast model, leading to an RMSE of $21.6^{\circ}$ [16]. However, both FFT and LG wind direction retrieval methods are limited when there is a lack of wind streaks imaged by the SAR, especially at low wind speeds; one study indicated that MABL rolls were present in $44 \%$ of 1882 SAR images and completely absent in 34\% [18]. Furthermore, in another recent study, $\sim 48.0 \%$ of a data set of 227 SAR images displayed wind streaks; among those images, $67.3 \%, 20.0 \%$, and $12.7 \%$ occurred under unstable, neutral, and stable atmospheric conditions, respectively [19]. As mentioned above, these studies only focus on wind direction estimation under low to medium wind speed conditions, and they do not take into account the radar backscatter dependence on incidence angle.

For high winds, MABL rolls are prevalent in the TC boundary layer. The surface imprints of kilometer-scale roll vortices are clearly visible in the SAR images of hurricanes [20], [21]. In particular, 3-6-km wavelength roll vortices have been associated with secondary circulations between the main TC rain bands [1]. Other studies show that SAR can provide useful information for identifying TC MABL rolls and found that streak patterns in ocean surface roughness can be explained by changes in surface wind speed that are caused by the formation of rolls [11], [20], [22]. Previous research has shown that these streaks tend to be oriented so that they are approximately aligned with the wind direction [11], [15], [23]. Thus, from TC SAR images containing wind streaks, it is possible to retrieve wind directions. However, we should also address that the directions of wind streak are not always in line with wind direction. Researchers have used the LG method, or the FFT method, to obtain hurricane wind directions from the streaks in SAR images acquired only at $\mathrm{HH}$ - or VV-polarization [2], [24], and there was no investigation of the possible benefit of using the VH-polarization. In addition, the retrieved wind directions were not validated using in situ buoy and Global Positioning System (GPS) dropsonde measurements, scatterometer, and radiometer observations. Moreover, co-polarized radar backscatter becomes saturated as wind speeds approach hurricane-force winds. Therefore, the signatures of wind streaks may not be very clear between the TC eyes and the maximum wind radius (MWR) where the strongest winds generally occur. Compared to VV-polarization, radar backscatter acquired at VH-polarization is much less sensitive to radar incidence angle or wind direction and increases as wind speed increases, especially in TCs [4] and particularly near TC eyes (see [7, Fig. 2(b) and (c)]). Furthermore, VH-polarized radar backscattering does not show obvious saturation, even when the wind speed is close to $50 \mathrm{~m} / \mathrm{s}$ [5]-[7]. High backscatter in the eyewall area and low backscatter in the eye and peripheral storm regions are clearly found in the VH-polarized SAR TC images (see [25, Fig. 3]). The advantage of VV-polarization over VH-polarization is that the former has higher signal-to-noise ratio (SNR) in low wind speed areas than the latter. This low SNR is expected to affect the detection of streaks in cross-polarization images for the lowest wind speeds. Therefore, a combination of both VV-and $\mathrm{VH}$-polarization SAR measurements is probably necessary to fully exploit the potential of both polarizations and to maximize TC wind direction retrievals from SAR images. Note that a different and complementary approach [26] has also been recently proposed to combine SAR backscattering with Doppler measurements in order to minimize the use of external data for wind field retrieval. This method is not considered here and requires an accurate attitude control system of the satellite platform and the antenna pointing direction in order to properly get the geophysical contribution to the Doppler centroid estimation from SAR.

The goal of this article is to retrieve hurricane wind direction without ambiguity based on the computation of LGs over the wind-induced streaks in SAR imagery. Koch [15] pioneered the idea of LG method, which was used to directly estimate wind directions with ambiguities from single-polarization SAR imagery. In this study, we apply this approach to derive TC wind directions. It should be noted that our method is to use C-band RADARSAT-2 and Sentinel-1A to rely on both co- and cross-polarized channels. Moreover, we remove wind directions ambiguities according to TC's wind field 
TABLE I

TC SAR IMAGES AND THE COLLOCATED WIND DATA FOR WIND DIRECTION RETRIEVAL AND VALIDATION

\begin{tabular}{|c|c|c|c|c|c|}
\hline $\begin{array}{c}\text { TC } \\
\text { Name }\end{array}$ & Satellite & Date & $\begin{array}{l}\text { Time } \\
\text { (UTC) }\end{array}$ & $\begin{array}{l}\text { Collocated } \\
\text { wind data }\end{array}$ & $\begin{array}{c}\text { Time } \\
\text { (UTC) }\end{array}$ \\
\hline Bertha & RS2 & $\begin{array}{l}\text { Jul } 12 \\
2008\end{array}$ & $10: 14$ & QuikSCAT & 09:42 \\
\hline Earl & RS2 & $\begin{array}{c}\text { Aug } 30 \\
2010\end{array}$ & $09: 57$ & Buoy & $10: 00$ \\
\hline Earl & RS2 & $\begin{array}{l}\text { Sep } 2 \\
2010\end{array}$ & $22: 59$ & $\begin{array}{c}\text { Buoy, \& } \\
\text { GPS } \\
\text { dropsonde }\end{array}$ & $\begin{array}{c}23: 00 \& \\
16: 59- \\
04: 59\end{array}$ \\
\hline Arthur & RS2 & $\begin{array}{l}\text { Jul } 3 \\
2014\end{array}$ & $11: 13$ & Buoy & $11: 10$ \\
\hline $\begin{array}{c}\text { Rammas } \\
\text { un }\end{array}$ & $\mathrm{RS} 2$ & $\begin{array}{c}\text { Jul } 17 \\
2014\end{array}$ & $10: 27$ & Buoy & $11: 00$ \\
\hline Edouard & $\mathrm{RS} 2$ & $\begin{array}{c}\text { Sep } 14 \\
2014\end{array}$ & 09:05 & WindSat & 09:30 \\
\hline Dophin & RS2 & $\begin{array}{l}\text { May15 } \\
2015\end{array}$ & $08: 37$ & Buoy & $08: 42$ \\
\hline Soudelor & RS2 & $\begin{array}{l}\text { Aug } 3 \\
2015\end{array}$ & $20: 31$ & WindSat & $21: 06$ \\
\hline Lester & S1A & $\begin{array}{c}\text { Aug } 31 \\
2016\end{array}$ & $03: 15$ & WindSat & 03:00 \\
\hline Meranti & RS-2 & $\begin{array}{l}\text { Sep } 12 \\
2016\end{array}$ & $21: 28$ & WindSat & $22: 00$ \\
\hline
\end{tabular}

RS2 and S1A denote RADARSAT-2 and Sentinel-1A, respectively.

structure characteristics. The benefit of using each polarization is discussed, and the retrieved wind directions are validated against buoy and GPS dropsonde observations, scatterometer, and radiometer measurements.

The remainder of this article is organized as follows. Section II describes the data set. In Section III, the method for wind direction retrieval is introduced. In Section IV, we present the wind direction retrieval and validation results. Finally, the summary and conclusion are given in Section V.

\section{DATA SET}

For this study, we collected ten RADARSAT-2 and Sentinel-1A SAR images of TCs in the North Atlantic Ocean, East Pacific Ocean, and West Pacific Ocean. These images were collocated with wind measurements from in situ buoys, dropsondes, scatterometer, or radiometer measurements. Table I summarizes the SAR images and the collocated wind data. We use this collocated data set to validate SAR-derived wind directions.

\section{A. RADARSAT-2 and Sentinel-1A SAR Data}

C-band RADARSAT-2 SAR can provide single-polarization $(\mathrm{HH}, \mathrm{VV}, \mathrm{HV}$, or $\mathrm{VH})$, dual-polarization $(\mathrm{VV}+\mathrm{VH}$ or $\mathrm{HH}+\mathrm{HV})$, and quad-polarization $(\mathrm{HH}+\mathrm{HV}+\mathrm{VH}+\mathrm{VV})$ imaging modes with a different swath coverage. This study focuses on measurements from the dual-polarization $(\mathrm{VV}+\mathrm{VH})$ ScanSAR wide-imaging mode, which provides wide-swath $(500 \mathrm{~km})$ images suitable for monitoring TCs from space. ScanSAR wide mode has a range of incidence angles between $20^{\circ}$ and $49^{\circ}$. The pixel spacing is $50 \mathrm{~m} \times 50 \mathrm{~m}$, and the resolution is 163-73 and 78-106 $\mathrm{m}$ (range by azimuth). The noise equivalent sigma zero (NESZ) of this mode is about $-28 \pm 2 \mathrm{~dB}$ [27]. Moreover, we also collected Sentinel-1A dual-polarization SAR imagery, which was acquired in extended wide-swath (EW) imaging mode. The EW swath is $400 \mathrm{~km}$ wide and covers incidence angles from about $23.7^{\circ}$ to $44.5^{\circ}$. The pixel spacing is $40 \mathrm{~m} \times 40 \mathrm{~m}$, and the resolutions are 90.8-95.1 and 90.1-90.13 $\mathrm{m}$ in the range and azimuth directions, respectively. The NESZ of this mode ranges from -26 to $-37 \mathrm{~dB}$ and decreases with increasing incidence angle [28]. We note that the two sensors have comparable NESZ.

\section{B. QuikSCAT Data}

We use QuikSCAT surface wind fields from the Remote Sensing Systems (RSS) website (www.remss.com/mission/ qscat/). QuikSCAT Level 3 (L3) data consist of global grid values of meridional and zonal components of winds, measured twice a day at approximately $0.25^{\circ} \times 0.25^{\circ}$ resolution. The mission requirements for QuikSCAT have an accuracy of 2-m/s RMSE for wind speeds in the range $3-20 \mathrm{~m} / \mathrm{s}, 10 \%$ RMSE for the range $20-30 \mathrm{~m} / \mathrm{s}$, and $20^{\circ} \mathrm{RMSE}$ in the wind direction for wind speeds ranging from 3 to $30 \mathrm{~m} / \mathrm{s}$ [29], [30]. QuikSCAT ocean wind vectors have been completely reprocessed using the new Ku-band GMF termed as $\mathrm{Ku}-2011$. This has greatly improved both wind speed and direction for strong winds, providing a significant benefit for QuikSCAT Ku-2011 wind directions at high wind speeds up to $35 \mathrm{~m} / \mathrm{s}\left(\mathrm{RMSE}=9^{\circ}\right)$, compare to the $\mathrm{Ku}-2001$ $\left(\right.$ RMSE $\left.=15^{\circ}\right)[31]$. Note that the QuikSCAT Ku-2011 (V04) wind speeds have been calibrated to rain-free WindSat data. Rain exerts an important impact on Ku-band scatterometer wind retrieval, leading to a positive bias at low wind speeds due to signal backscatter by rain drops and a negative bias at high wind speeds due to atmospheric attenuation of the signals. The wind direction is less affected by rain, except at high rain rates (above $8 \mathrm{~mm} / \mathrm{h}$ ) [32]. QuikSCAT Ku-2011 (V04) products provide wind data in both rain-free and rainy areas. In this article, we only compare SAR-retrieved wind directions with those from QuikSCAT under low rain rates (below $8 \mathrm{~mm} / \mathrm{h}$ ).

\section{WindSat Data}

WindSat has been designed to show the capability of polarimetric microwave radiometry to measure ocean wind vectors [33]. By using multiple polarimetric channels $(10-37 \mathrm{GHz}$, plus a linearly polarized channel at $6.8 \mathrm{GHz})$, WindSat can measure both wind speed and wind direction. An all-weather algorithm capable of global wind vector retrievals even in storm conditions was developed for WindSat [34]. The wind direction retrieval accuracy varies from about $10^{\circ}$ in light rain to $30^{\circ}$ in heavy rain. The radiometer wind direction accuracy decreases significantly in heavy rain because of the strong attenuation of signals. Since heavy rainfall have a significant effect on the wind 
direction retrieval accuracy of WindSat, we only compare SAR-retrieved wind directions with WindSat wind directions under very low rain rates (below $1 \mathrm{~mm} / \mathrm{h}$ ). WindSat all-weather wind vector products with a spatial resolution of $0.25^{\circ} \times 0.25^{\circ}$ can be acquired through the RSS website (http://www.remss.com/missions/windsat/).

\section{Buoy Data}

Four SAR images were collocated with the National Data Buoy Center (NDBC) buoys located in the North Atlantic and the East Pacific Oceans. These buoys measured wind speeds and directions and reported values averaged over 8-min periods each hour. In each case, the buoys are located within the image footprint, and the SAR acquisition time is within 30 min of the buoy measurement. Moreover, in order to observe the upper ocean response to typhoons, we used a cross-shaped array of five moored buoys and four subsurface moorings that had been deployed in the Northern South China Sea in September 2014. Typhoon Rammasun passed over one of the buoys and was simultaneously imaged by RADARSAT- 2 .

\section{E. GPS-Dropsonde Data}

The GPS dropsonde is a very useful instrument for atmospheric measurements; it measures the vertical wind profile with accuracies of $0.5-2.0 \mathrm{~m} / \mathrm{s}$ and a vertical resolution of $\sim 5 \mathrm{~m}$ [35]. Dropsondes have been demonstrated to record the mean vertical profile of wind speed in the hurricane inner core from the surface to 700-hPa level [36]. From 1996 to 2012, National Oceanic and Atmospheric Administration (NOAA) had dropped 13681 dropsondes inside hurricane eyewalls or in the surrounding environment of $120 \mathrm{TCs}$, yielding a long-term and high-quality GPS dropsonde data set [37]. Recently, dropsonde-measured winds were also compared with airborne Doppler Wind Lidar (DWL) measurements during Tropical Storm Erika (2015) and showed good agreement in terms of both wind magnitude and asymmetric distribution of the wind field [38]. Moreover, GPS dropsonde wind observations during typhoons are compared with QuikSCAT retrievals, and a wind direction RMSE of $17^{\circ}$ is obtained [39]. In order to validate the SAR-derived wind directions in this study, we collocate the RADARSAT-2 SAR image of Hurricane Earl with dropsonde measurements. In total, there are 21 dropsondes that were collected during a time interval of $12 \mathrm{~h}$. Prior to making comparison with SAR-retrieved wind direction, dropsondes measurements are adjusted for the time difference between SAR acquisitions by shifting the movement of the storm center according to the time difference. The GPS dropsonde data can be acquired through the website (http://www.aoml.noaa.gov/hrd/data_sub/hurr.html).

The storm's movement is derived from the best track information from the National Hurricane Center (NHC), Miami, Fl, USA, best track data (https://www.nhc.noaa.gov/data/\#hurdat).

\section{Methodology}

For an idealized image with wind streaks, the pixel amplitude does not change significantly along the direction of

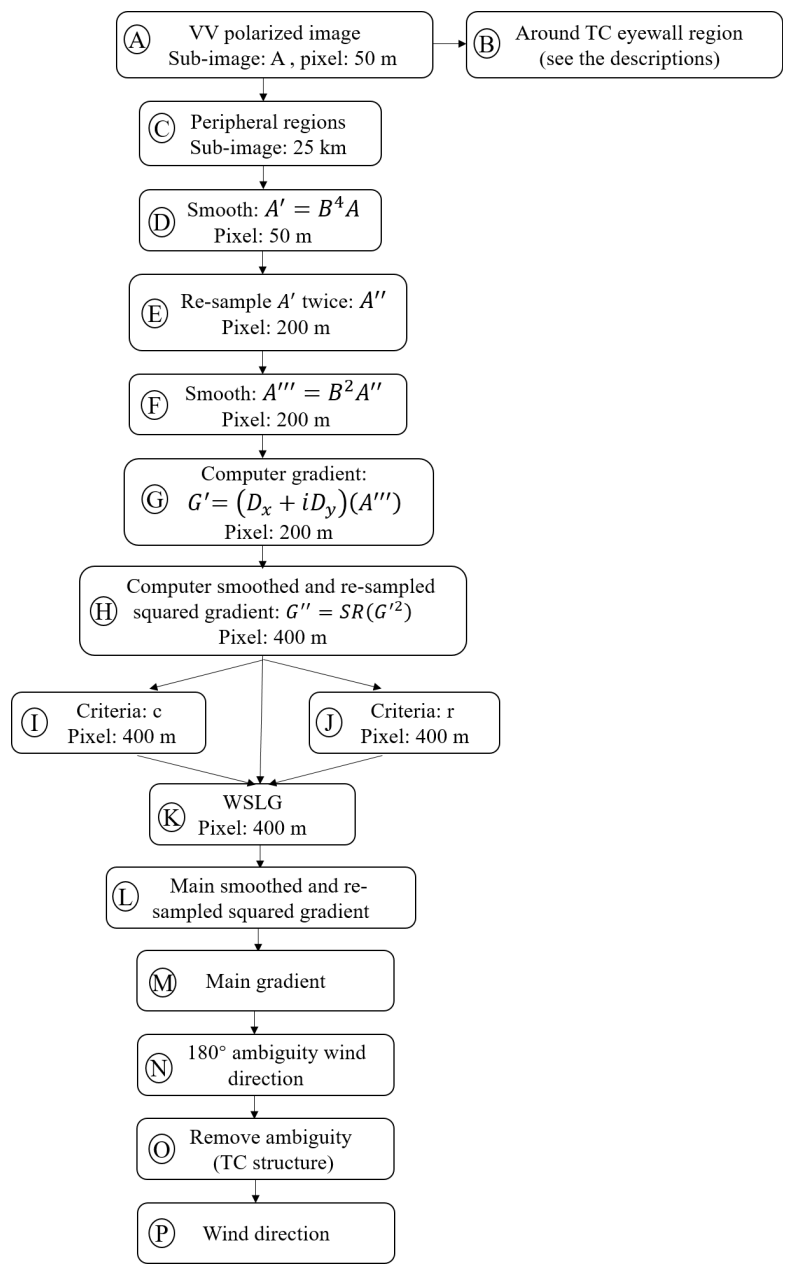

Fig. 1. Flowchart of the VV-polarized SAR wind direction retrieval.

the streak, but it varies dramatically in the perpendicular direction of the streaks. Since the image gradient is defined as a directional change in the intensity [40], the gradient direction is orthogonal to the direction of the wind streak. Wind direction is perpendicular to the direction of the gradient. In this study, we use the LG method [15] to estimate wind directions from C-band dual-polarization TC SAR images. This method computes the LGs and chooses the orthogonal of the most frequently computed gradient direction as a possible wind direction. We remove the $180^{\circ}$ wind direction ambiguity based on TC wind field structure characteristics. The flowchart of VV-polarized SAR wind direction retrieval is summarized in Fig. 1; this flowchart is identical to that of VH. In Sections III-A-III-E, we describe the procedure for wind direction retrieval, step by step.

\section{A. SAR Image Smoothing and Resampling}

Since speckle noise exists in any given SAR image, we need to smooth the SAR image to obtain accurate gradient directions. This is carried out with smoothing operators $B^{4}$ and $B^{2}$ before calculating LGs [15]. The first image smoothing is performed with the following convolution operation:

$$
A^{\prime}=B^{4} A
$$


where $A^{\prime}$ is the SAR image after the first smoothing (box D in the flowchart of Fig. 1), $A$ is the original SAR amplitude image (box C), $B^{4}$ is a binomial operator for the smoothing operation in various directions, namely,

$$
B^{4}=\frac{1}{256}\left[\begin{array}{ccccc}
1 & 4 & 6 & 4 & 1 \\
4 & 16 & 24 & 16 & 4 \\
6 & 24 & 36 & 24 & 6 \\
4 & 16 & 24 & 16 & 4 \\
1 & 4 & 6 & 4 & 1
\end{array}\right]
$$

In order to further remove the noise in the SAR image, we resample the SAR image by decreasing pixel spacing of image. Koch [15] suggested that images of the open ocean should be smoothed and resampled to 200-m pixel spacing when long ocean waves are present in the SAR images. In this study, VV- and VH-polarized backscatters are used to estimate LGs in TC peripheral regions (outside MWR). For TC eye center and eyewall areas (inside MWR), we use VH-polarized backscatters to calculate LGs. For different TCs, the images are resampled to $200-\mathrm{m}$ pixel spacing in TC peripheral regions, but the resampled pixel spacings are variable in the eyewall area. It should be noted that the selection of variable pixel spacing is different from constant value chosen in previous studies [15], [16] for the LG estimation. We resample the SAR images to 100-, 200-, 400-, 800-, or 1600-m pixel spacing in the eyewall region. The image resampling is done with lowpass filters. The resampled image is referred to as $A^{\prime \prime}$ (box E). The image $A^{\prime \prime \prime}$ (box F) is obtained by using the following convolution operation:

$$
A^{\prime \prime \prime}=B^{2} A^{\prime \prime}
$$

where

$$
B^{2}=\frac{1}{16}\left[\begin{array}{lll}
1 & 2 & 1 \\
2 & 4 & 2 \\
1 & 2 & 1
\end{array}\right] .
$$

After noise removal by image smoothing and resampling, we need to determine the subimage size for image gradient computation. For different TC areas, different sizes of subimage are different. We set the subimage size as $25 \mathrm{~km}$ in the TC peripheral region. In the TC eyewall area, the size of the subimage is ascertained by using information about the inflow angle and the MWR. According to the previous research, the TC inflow angle is approximately $20^{\circ}-25^{\circ}$ counter clockwise in the northern hemisphere [41]. Investigations have shown that the mean inflow angle in hurricanes is in the range of $-22.6^{\circ} \pm 2.2^{\circ}$ with $95 \%$ confidence [42]. In this study, based on the analysis of all cases, we observed that the minimum RMSE between the retrieved wind directions and the TC tangential directions occur when the inflow angle is $20^{\circ}$. Therefore, we set the inflow angle as $20^{\circ}$ and obtain the MWR based on a cross-polarization wind speed retrieval algorithm [6]. The initial size of the subimage is set as $1 \mathrm{~km}$, and the maximum of the subimage size is set at the value of the MWR. We estimate LG with different subimage sizes $(1,2$, ..., MWR) and different pixel spacings (100, 200, 400, 800, and $1600 \mathrm{~m}$ ). The optimum subimage size and pixel spacing are obtained when the relative angle between the retrieved wind directions and the tangential direction of the spiral line is nearest to the inflow angle.

\section{B. Computing the Local Gradients}

After image smoothing and resampling as well as subimage size and pixel spacing determination, we can estimate LGs in the subimage segments (box G). The gradient components of each subimage are computed with the Scharr operator [43]

$$
D_{x}=\frac{1}{32}\left[\begin{array}{ccc}
3 & 0 & -3 \\
10 & 0 & -10 \\
3 & 0 & -3
\end{array}\right]
$$

and its transpose

$$
D_{y}=D_{x}^{T} .
$$

Using (5) and (6), the gradients are computed from the smoothed and resampled amplitude image $A^{\prime \prime \prime}$

$$
G^{\prime}=\left(g_{m n}^{\prime}\right)=\left(D_{x}+i D_{y}\right)\left(A^{\prime \prime \prime}\right)
$$

where $m$ and $n$ denote the subscripts of the gradient image. Compared to the gradient $G^{\prime}$, the smoothed and resampled squared gradient (SRSG) $G^{\prime \prime}$ (box H) enhances the main gradient and attenuates the secondary gradient

$$
G^{\prime \prime}=\left(g_{m^{\prime} n^{\prime}}^{\prime \prime}\right)=\operatorname{SR}\left(g_{m n}^{\prime 2}\right) .
$$

In (8), SR operation represents the smoothing of the image, resampling, and once again smoothing, which has the same meaning with " $R_{\mid 2}$ " in [15]. The procedure is the same as the SAR amplitude image processing mentioned above in Section III-A. The values $m^{\prime}$ and $n^{\prime}$ denote the subscripts of the SRSG image. In the TC peripheral region, after the SR operation, the pixel size of the SRSG is $400 \mathrm{~m}$. Once the main SRSG of each subimage is known, we can obtain the main gradient information by taking the square root of the main SRSG. In order to accurately calculate the main SRSG, two qualifying criteria (boxes I and J) are introduced following [15]. The first one is used to measure the directional coherency. The larger the $c_{m^{\prime} n^{\prime}}$, the more favorable it is to extract the main SRSG

$$
0 \leq c_{m^{\prime} n^{\prime}}=\frac{\left|g_{m^{\prime} n^{\prime}}^{\prime \prime}\right|}{g_{m^{\prime} n^{\prime}}^{\prime \prime \prime}} \ll 1
$$

where

$$
G^{\prime \prime \prime}=\left(g_{m^{\prime} n^{\prime}}^{\prime \prime \prime}\right)=\operatorname{SR}\left(\left|g_{m n}^{\prime 2}\right|\right) .
$$

The second qualifying criteria is computed from the magnitude of the SRSG

$$
0 \ll r_{m^{\prime} n^{\prime}}=\frac{\left|g_{m^{\prime} n^{\prime}}^{\prime \prime}\right|}{\left|g_{m^{\prime} n^{\prime}}^{\prime \prime}\right|+\operatorname{median}\left(\left|g_{p^{\prime} q^{\prime}}^{\prime \prime}\right|\right)}<1 .
$$

In (11), $p^{\prime}$ and $q^{\prime}$ denote the subscripts of the selected subimage. The second term in the denominator is the median of the magnitudes of the SRSG for the selected subimage. Again, the larger the $r_{m^{\prime} n^{\prime}}$, the more appropriate it is to extract the main SRSG. 

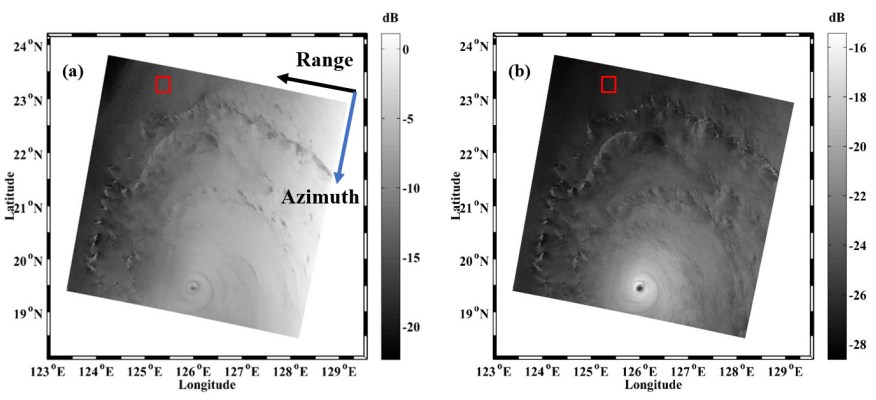

Fig. 2. RADARSAT-2 dual-polarization SAR image acquired over Typhoon Meranti on September 12, 2016, at 21:28 UTC showing (a) VV-polarization and (b) VH-polarization, where the color bar shows $\sigma_{0}(\mathrm{~dB})$ in VV-polarization $\left(\sigma_{\mathrm{VV}}^{0}\right)$ and in VH-polarization $\left(\sigma_{\mathrm{VH}}^{0}\right)$, respectively. Red square denotes the selected subimage $(25 \mathrm{~km} \times 5 \mathrm{~km})$, and black and blue arrows denote the look and azimuth directions of radar, respectively. RADARSAT-2 Data and Product MacDonald, Dettwiler, and Associates Ltd. All Rights Reserved.

\section{Extracting the Main Directions}

The main SRSG direction of a subimage is determined by finding the maximum of weighted-squared local gradient (WSLG) in the smoothed histogram. The directional values of SRSG are sorted into 72 directional intervals of $5^{\circ}$ each. For each interval, the WSLG (box K) is estimated as follows:

$$
\mathrm{WSLG}_{m^{\prime} n^{\prime}}=\frac{G_{m^{\prime} n^{\prime}}^{\prime \prime}}{\left|G_{m^{\prime} n^{\prime}}^{\prime \prime}\right|}\left(c_{m^{\prime} n^{\prime}}+r_{m^{\prime} n^{\prime}}\right) \text {. }
$$

The WSLG histogram is smoothed with the terms $B_{8 x}^{2} B_{4 x}^{2} B_{2 x}^{2} B_{x}^{2}$ from (4) and interpolated. The definitions of these operators are given by the following equations:

$$
\begin{aligned}
B_{x}^{2} & =\frac{1}{4}\left(\begin{array}{llll}
1 & 2 & 1
\end{array}\right) \\
B_{2 x}^{2} & =\frac{1}{4}\left(\begin{array}{llllll}
1 & 0 & 2 & 0 & 1
\end{array}\right) \\
B_{4 x}^{2} & =\frac{1}{4}\left(\begin{array}{lllllllll}
1 & 0 & 0 & 0 & 2 & 0 & 0 & 0 & 1
\end{array}\right) \\
B_{8 x}^{2} & =\frac{1}{4}\left(\begin{array}{lllllllllllllllll}
1 & 0 & 0 & 0 & 0 & 0 & 0 & 0 & 2 & 0 & 0 & 0 & 0 & 0 & 0 & 0 & 1
\end{array}\right) .
\end{aligned}
$$

The maximum of the WSLG magnitudes in the smoothed and interpolated histogram gives the main SRSG (box L). The square root of the main SRSG gives the main gradient (box M), and the orthogonal to the main gradient defines the main wind direction to be searched for, which still retains the $180^{\circ}$ ambiguity (box $\mathrm{N}$ ). It should be noted that we can obtain a wind direction in each subimage, but in some subimages, the wind directions are obviously wrong. Thus, in TC peripheral regions, we introduce a minimum threshold for the maximum of the smoothed WSLG magnitude. Based on an analysis of all available SAR imagery for the maximum WSLG, this threshold is set as a constant value of 45 . Below this value, the LG estimation is considered as poor quality. In the TC eyewall area, the threshold is set as the average value of the WSLG magnitude.

Fig. 2 shows a RADARSAT-2 dual-polarization SAR image acquired over Typhoon Meranti on September 12, 2016, at 21:28 UTC. As shown in Fig. 2, the VH-polarization SAR image is better able to delineate the structural features of
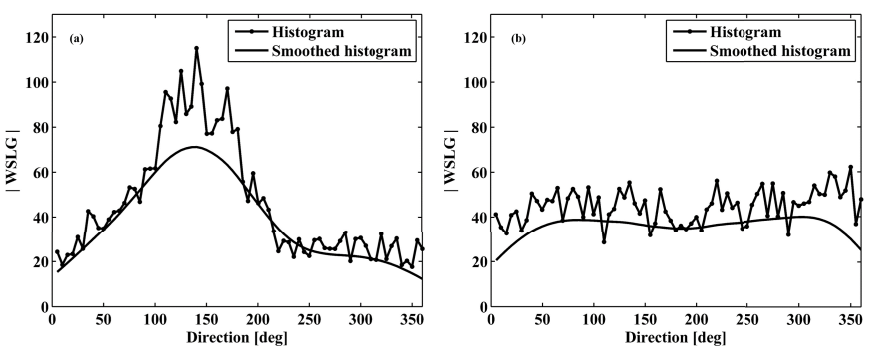

Fig. 3. Histogram of magnitudes of WSLG estimated with SAR subimage acquired in (a) VV-polarization and (b) VH-polarization. The abscissa axis does not only represent the main gradient or the wind direction but also denotes the general direction to find the WSLG magnitude.
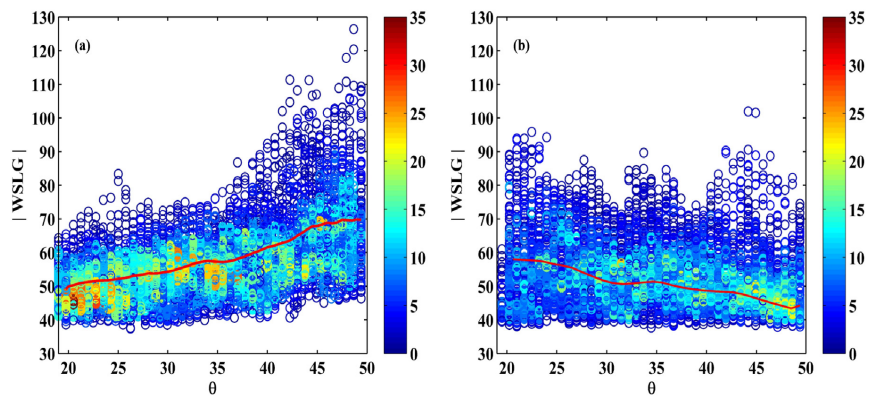

Fig. 4. Magnitudes of WSLG versus radar incidence angle. (a) VV-polarization and (b) VH-polarization.

the typhoon due to the modifications of the ocean surface waves than VV-polarization. This is because cross-polarized radar backscatters are much less sensitive to ocean surface wind directions and incidence angles than VV. In Fig. 2, the incidence angle dependency of VV-mode explains the strong and nongeophysical contrast observed in the SAR image in the range direction. Based on (12), we can estimate the WSLG within a $25-\mathrm{km}$ subimage indicated by a red box in the VV- and VH-polarized SAR images.

Fig. 3(a) and (b) illustrates the histograms of estimated WSLG magnitudes for VV- and VH-polarizations for this particular subimage. The histogram of the WSLG for the 72 directional bins is found to exhibit more directional variation for the VV data than for the VH data. This illustrates the higher sensitivity of VV-polarization to the signature of wind rolls than VH-polarization in TC peripheral regions. In Fig. 3, the abscissa axis does not only represent the main gradient or the wind direction but also denotes the general direction to find the WSLG magnitude. As shown in Fig. 3(a), the maximum WSLG magnitude is 71. Before taking the magnitude, the WSLG value is a complex number, which is $48.42-51.93 i$. Thus, the estimated main SRSG direction is $180^{\circ}-\arctan (48.42 / 51.93)=137^{\circ}$, and the resulting main gradient is $\sqrt{48.42-51.93 i}=7.73-3.36 i$. The direction of the main gradient is $180^{\circ}-\arctan (7.73 / 3.36)=113^{\circ}$, and the wind direction is $113^{\circ}-90^{\circ}=23^{\circ}$ or alternately, $113^{\circ}+90^{\circ}=203^{\circ}$.

Taking account of all available SAR images, we also analyze the variation of the WSLG magnitudes with respect to radar incidence angles. This is presented in Fig. 4(a) and (b), respectively, for VV- and VH-polarizations. We observe that 


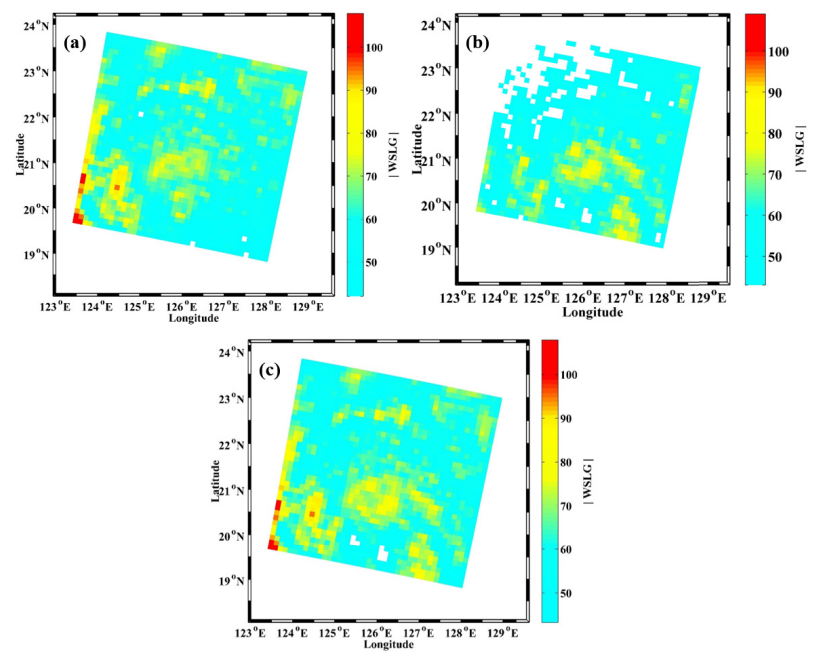

Fig. 5. Maximum of the smoothed WSLG magnitude of Typhoon Meranti estimated with SAR image acquired in (a) VV-polarization, (b) VH-polarization, and (c) dual-polarization $(\mathrm{VV}+\mathrm{VH})$.

the maximum WSLG increases with incidence angles for VV. In particular, for the largest incidence angles $\left(40^{\circ}-49^{\circ}\right)$, the maximum WSLG for VV are much larger than 45 . This can be explained by the higher relative impact of Bragg waves (centimeter waves which are more sensitive than longer waves) on the co-polarization normalized radar cross-section (NRCS) variations at C-band, as the incidence angle increases [44]. On the contrary, the maximum WSLG is found to be close to, or below, 45 for VH. The weak dependence of the WSLG on incidence angle is certainly due to the weak incidence angle dependence of the NRCS. Moreover, the low SNR explains why the maximum WSLG amplitude is generally lower in $\mathrm{VH}$ than in VV. Therefore, we propose to combine maximum WSLG estimates from VV- and VH-polarizations to retrieve the wind direction from the highest quality WSLG.

The estimated maximum WSLG of each subimage for the entire collection of SAR images (presented in Fig. 2) is shown in Fig. 5. The blank areas indicate that the maximums of the smoothed WSLG magnitudes in the associated subimages are below the threshold mentioned above. As observed, there is a complementarity between the two polarizations [see Fig. 5(a) and (b)]. In particular, we observe higher quality for WSLG near the hurricane eye in VH than in VV. We also note more blank areas far from the hurricane center in VH than in VV. Thus, after combining both VV- and VH-polarization SAR measurements, the areas left with poor quality results for WSLG are reduced [see Fig. 5(c)].

The direction corresponding to the square root of the maximum of the smoothed WSLG gives the orientation of the main gradient in each subimage. Since wind direction is perpendicular to the main gradient direction, the wind direction (with $180^{\circ}$ ambiguity) in each subimage is then directly derived from the main gradient direction.

\section{Wind Direction Ambiguity Removal}

The wind direction ambiguities are removed by assuming the expected TC wind direction structure in the northern

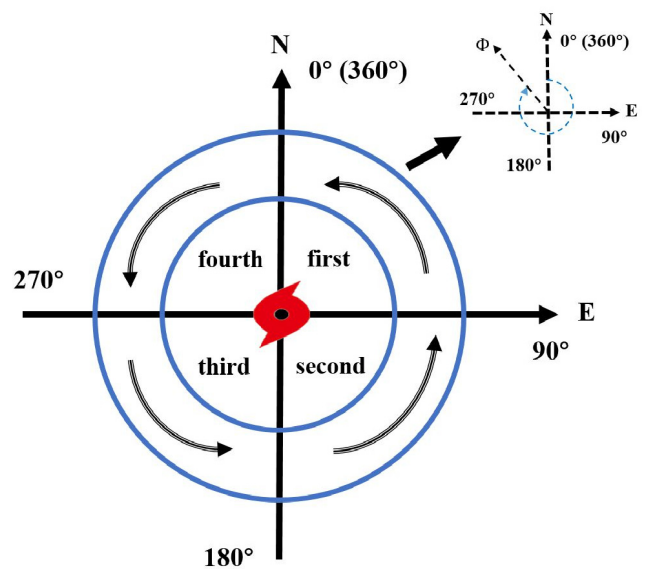

Fig. 6. Diagram of typical TC wind direction structure in the northern hemisphere. The black arrows are wind directions.

hemisphere (this study is only dealing with TCs in this hemisphere; box O) as shown in Fig. 6. The wind direction ambiguity removal procedure is divided into three steps: 1) determine the $\mathrm{TC}$ eye center position based on the technique proposed in [45]; 2) ascertain the quadrant for the appropriate subimage, according to the positions of the eye center and the position of this specific subimage; and 3) derive the unique wind direction based on the following criteria.

If the subimage is in the first quadrant, then

$$
270^{\circ}<\Phi<360^{\circ} .
$$

If the subimage is in the second quadrant, then

$$
0^{\circ}<\Phi<90^{\circ} \text {. }
$$

If the subimage is in the third quadrant, then

$$
90^{\circ}<\Phi<180^{\circ} \text {. }
$$

If the subimage is in the fourth quadrant, then

$$
180^{\circ}<\Phi<270^{\circ}
$$

where $\Phi$ is the wind direction.

\section{E. Interpolation}

Fig. 7(a) and (b) shows the SAR-derived wind directions for Typhoon Meranti based on only VV- or VH-polarized SAR images, respectively. For VH wind direction retrieval, most of the areas where no wind direction can be derived correspond to large incidence angles associated with low wind speeds. The combination of VV- and VH-polarized SAR images yields to the results shown in Fig. 7(c). As expected, the wind directions in Fig. 7(c) are now much better resolved, compared to Fig. 7(a) or (b). However, areas without wind directions are still evident, associated with WSLG magnitudes lower than 45. To overcome this issue, we apply a bilinear interpolation to obtain wind directions for the entire image. The results are shown in Fig. 7(d). 

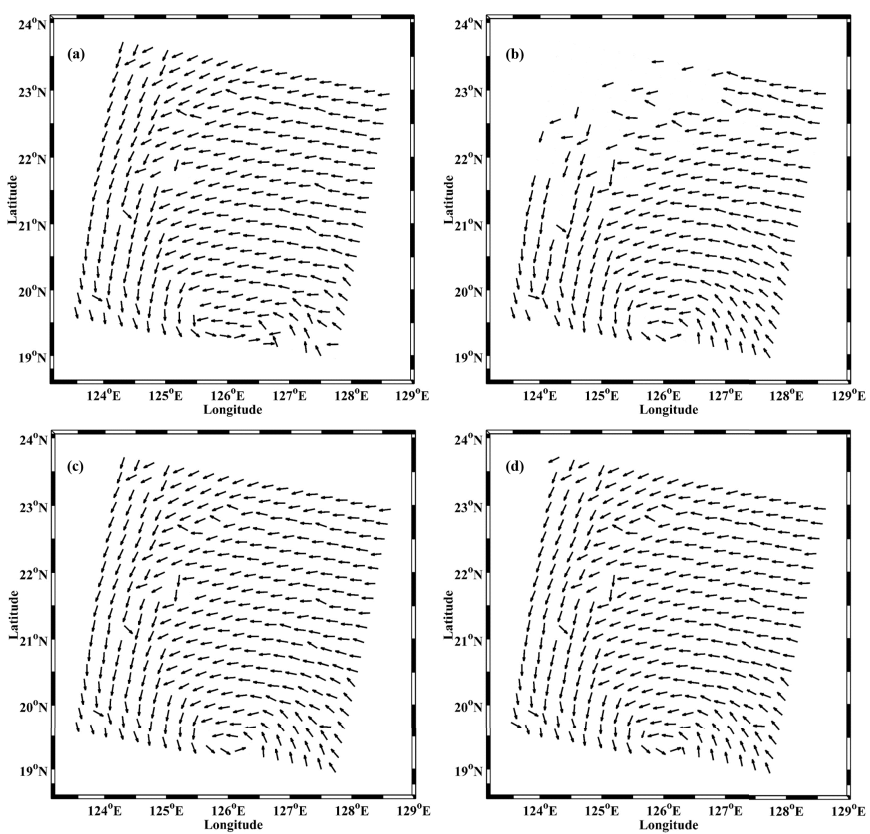

Fig. 7. SAR-retrieved wind directions of Typhoon Meranti on September 12, 2016, at 21:28 UTC, with image of (a) VV-polarization, (b) VH-polarization, (c) dual-polarization (VV $+\mathrm{VH})$, and (d) dualpolarization $(\mathrm{VV}+\mathrm{VH})$ and interpolation processing.

\section{RESUlts AND Discussion}

In this study, we first applied the LG method to retrieve the wind directions in TCs. Subsequently, we now assess our methodology for SAR-retrieved wind directions using collocated wind directions from buoys, GPS dropsondes, QuikSCAT, and WindSat data. To validate the proposed wind direction retrieval method, we choose nearest distance criteria for comparison.

In the case of Typhoon Meranti, we collocated the RADARSAT-2 SAR observation with WindSat measurements to illustrate the methodology, as discussed in Section III. The time interval between SAR observation and WindSat measurements is $22 \mathrm{~min}$. The determination of collocation is based on the nearest distance criteria. Fig. 8 illustrates the wind directions from our dual-polarization SAR retrievals and those from WindSat measurements. For this case, when estimating the LG, the subimage size and pixel spacing are set as $25 \mathrm{~km}$ and $200 \mathrm{~m}$ in the TC peripheral region and $8 \mathrm{~km}$ and $800 \mathrm{~m}$ in the TC eyewall area, respectively. Quantitative comparisons between SAR-retrieved wind directions and WindSat measurements are shown in Fig. 9. Wind directions from VV-polarized SAR have a bias of $-4.14^{\circ}$ and an RMSE of $16.18^{\circ}$; for VH-polarized SAR, the bias and RMSE are $2.93^{\circ}$ and $16.66^{\circ}$; whereas for the dual-polarized SAR, the bias and RMSE are $-2.63^{\circ}$ and $15.15^{\circ}$, respectively.

Fig. 10 shows a RADARSAT-2 dual-polarization SAR image acquired over Hurricane Bertha on July 12, 2008, at 10:14 UTC. The SAR-retrieved wind directions are shown in Fig. 11. This example also shows the complementarity of the two polarizations, both far from, and close to, the hurricane eye area. Fig. 12 illustrates the wind directions from dual-polarization SAR retrievals and the collocated
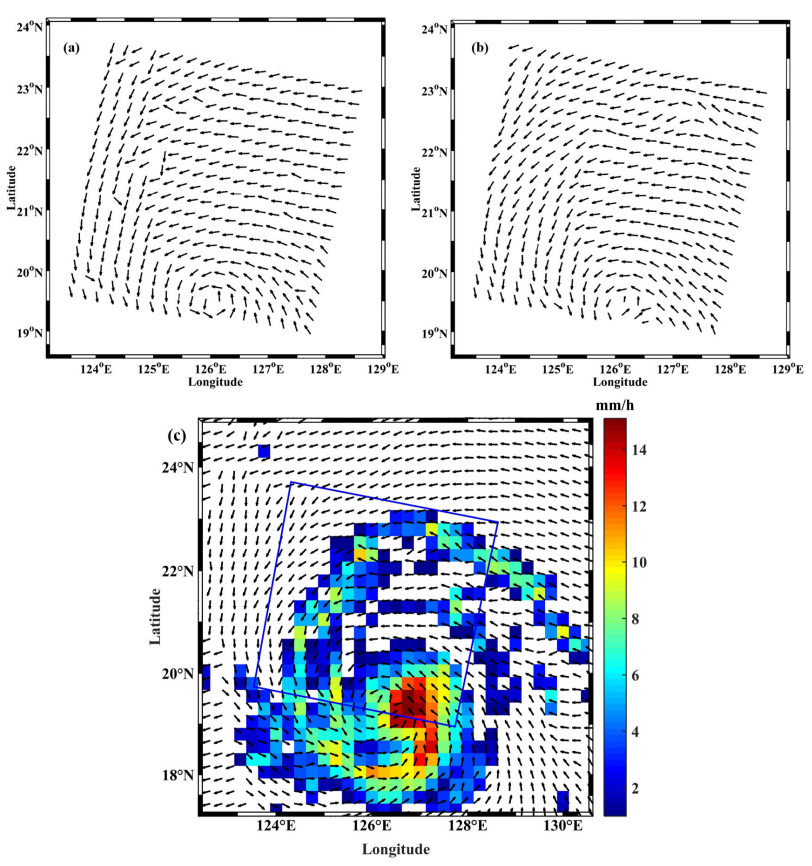

Fig. 8. (a) Dual-polarization SAR-retrieved wind directions of Typhoon Meranti on September 12, 2016, at 21:28 UTC. (b) WindSat-measured wind directions which are shown in the blue box of (c). (c) WindSat-measured wind directions on September 12, 2016, at 22:00 UTC, where the color bar denotes the rain rate $(\mathrm{mm} / \mathrm{h})$.

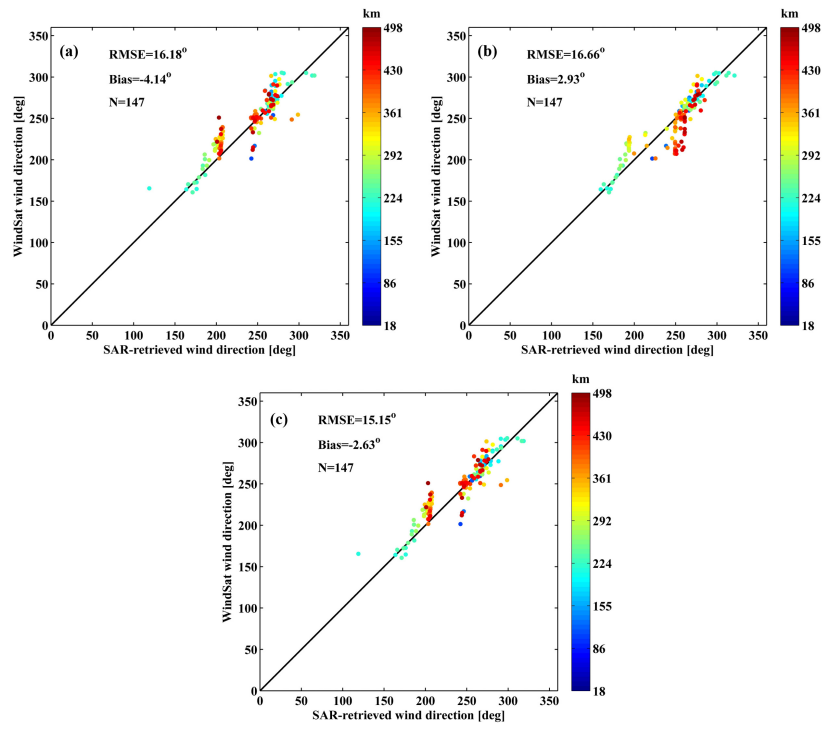

Fig. 9. (a) VV-polarization SAR-retrieved wind directions versus WindSat-measured wind directions. (b) VH-polarization SAR-retrieved wind directions versus WindSat-measured wind directions. (c) Dual-polarization $(\mathrm{VV}+\mathrm{VH})$ SAR-retrieved wind directions versus WindSat-measured wind directions. The color bar denotes the radius from storm center. Typhoon Meranti wind directions from SAR and WindSat are acquired on September 12, 2016, at 21:28 UTC, and on September 12, 2016 , at 22:00 UTC, respectively.

QuikSCAT measurements. For this case, when estimating LGs, the subimage size and pixel spacing are set as $25 \mathrm{~km}$ and $200 \mathrm{~m}$ in the TC peripheral region and $4 \mathrm{~km}$ and $400 \mathrm{~m}$ in the TC eyewall area. For this case, the time interval between the SAR image and the QuikSCAT observations 

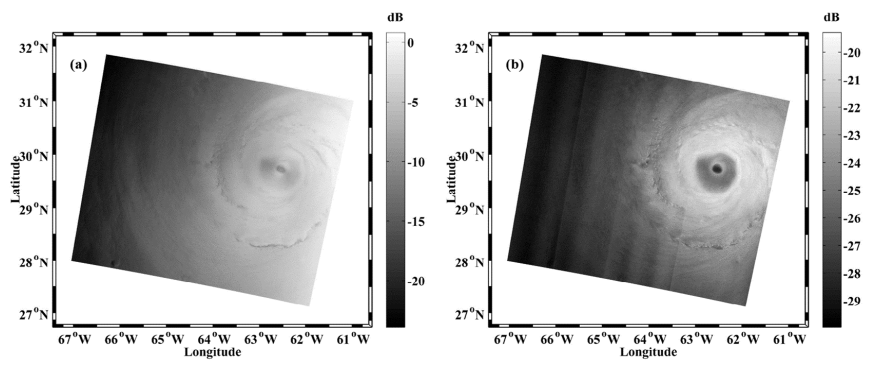

Fig. 10. RADARSAT-2 dual-polarization SAR image acquired over Hurricane Bertha on July 12, 2008, at 10:14 UTC showing (a) VV-polarization and (b) VH-polarization, where the color bar shows $\sigma_{0}(\mathrm{~dB})$ in VV-polarization $\left(\sigma_{\mathrm{VV}}^{0}\right)$ and in VH-polarization $\left(\sigma_{\mathrm{VH}}^{0}\right)$, respectively. RADARSAT-2 Data and Product MacDonald, Dettwiler, and Associates Ltd., All Rights Reserved.
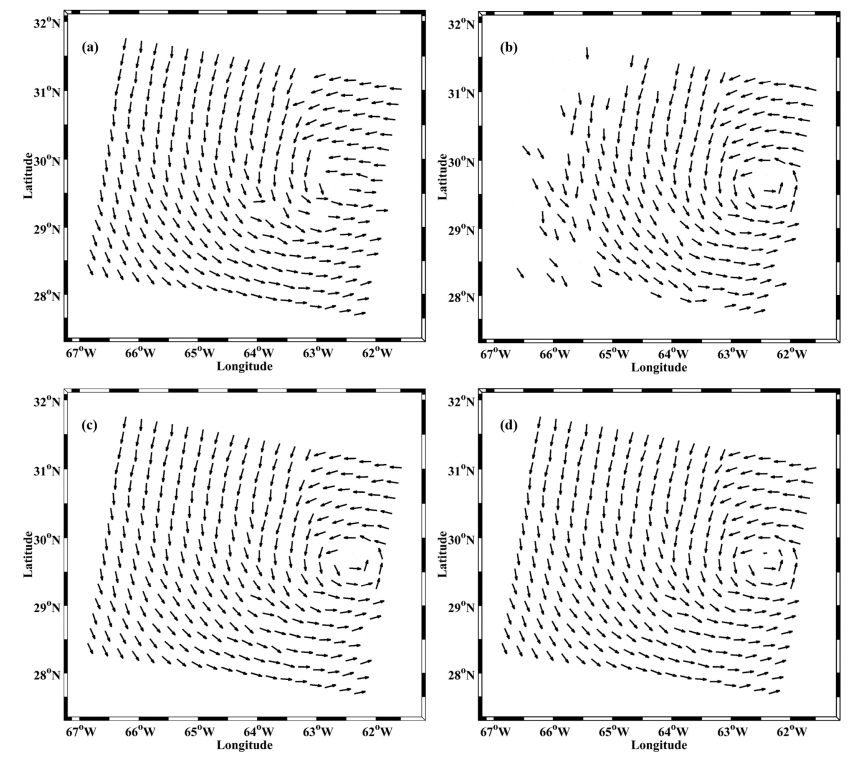

Fig. 11. SAR-retrieved wind directions of Hurricane Bertha on July 12, 2008, at 10:14 UTC, with image of (a) VV-polarization, (b) VH-polarization, (c) dual-polarization $(\mathrm{VV}+\mathrm{VH})$, and (d) dual-polarization $(\mathrm{VV}+\mathrm{VH})$ and interpolation processing.

is $32 \mathrm{~min}$. Fig. 13 shows a comparison between SAR-retrieved and QuikSCAT-measured wind directions. Wind directions from VV-polarized SAR have a bias of $3.01^{\circ}$ and an RMSE of $15.21^{\circ}$; for $\mathrm{VH}$-polarized SAR, the bias and RMSE are $2.28^{\circ}$ and $24.39^{\circ}$; whereas for dual-polarized SAR, the bias and RMSE are $4.50^{\circ}$ and $9.94^{\circ}$ after interpolation, respectively. The difference between SAR retrieval and QuikSCAT measurement may be caused by the wind direction interpolation operator.

Fig. 14 shows a RADARSAT-2 dual-polarization SAR image acquired over Hurricane Earl on September 2, 2010, at 22:59 UTC. Since no available radiometer or scatterometer wind measurements could be matched to the SAR images of Hurricane Earl, we used collocated SAR retrievals and GPS dropsonde measurements to evaluate the accuracy of the wind direction retrieval. Fig. 15 shows SAR-retrieved wind directions. For this case, when estimating LGs, the subimage sizes and pixel spacing are set as $25 \mathrm{~km}$ and $200 \mathrm{~m}$

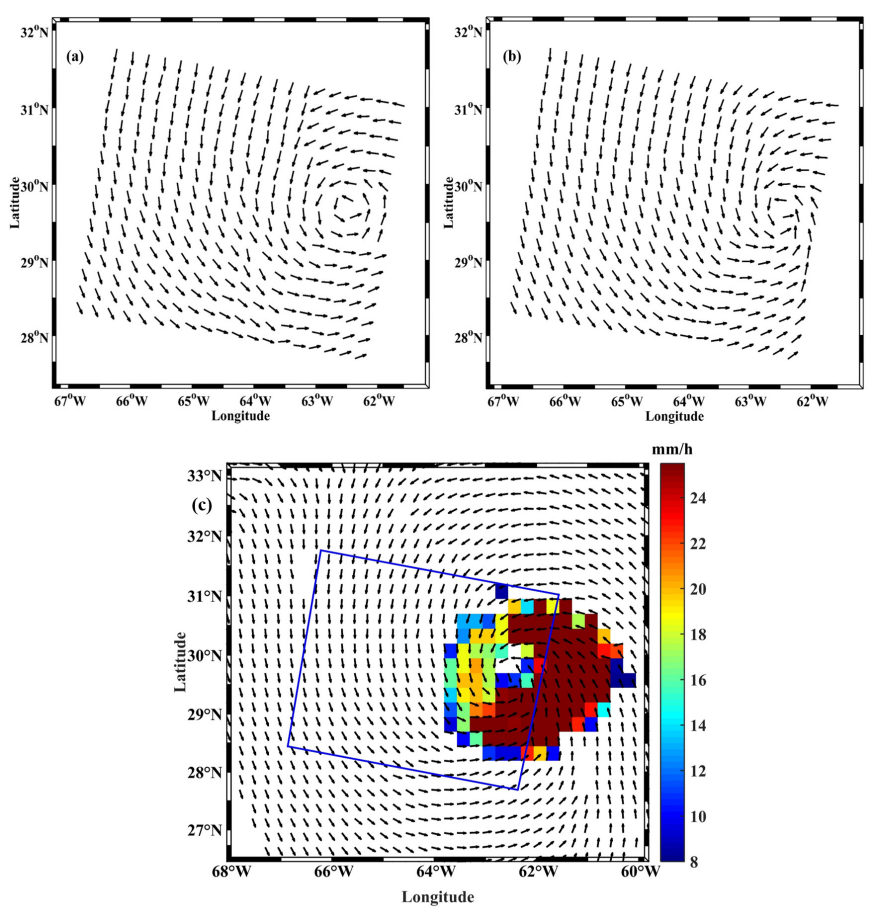

Fig. 12. (a) Dual-polarization SAR-retrieved wind directions of Hurricane Bertha on July 12, 2008, at 10:14 UTC. (b) QuikSCAT-measured wind directions which are shown in the blue box in (c). (c) QuikSCAT-measured wind directions on July 12, 2008, at 09:42 UTC, where the color bar denotes the rain rate $(\mathrm{mm} / \mathrm{h})$.

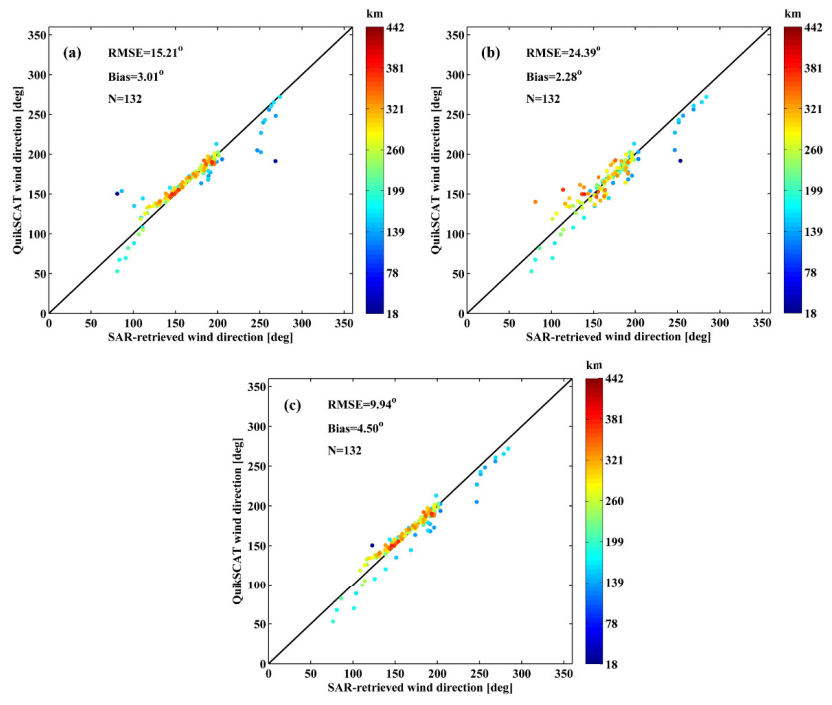

Fig. 13. (a) VV-polarization SAR-retrieved wind directions versus QuikSCAT-measured wind directions. (b) VH-polarization SAR-retrieved wind directions versus QuikSCAT-measured wind directions. (c) Dualpolarization (VV $+\mathrm{VH})$ SAR-retrieved wind directions versus QuikSCATmeasured wind directions. The color bar denotes the radius from storm center. Hurricane Bertha wind directions from SAR and QuikSCAT are acquired on July 12, 2008, at 10:14 UTC, and on July 12, 2008, 09:42 UTC, respectively.

in the TC peripheral region and $4 \mathrm{~km}$ and $200 \mathrm{~m}$ in the TC eyewall area, respectively. Fig. 16 shows a comparison between SAR-retrieved and dropsonde measurements for wind directions. Wind directions from VV-polarized SAR have a bias of $2.24^{\circ}$ and an RMSE of $59.98^{\circ}$; for $\mathrm{VH}$-polarized 


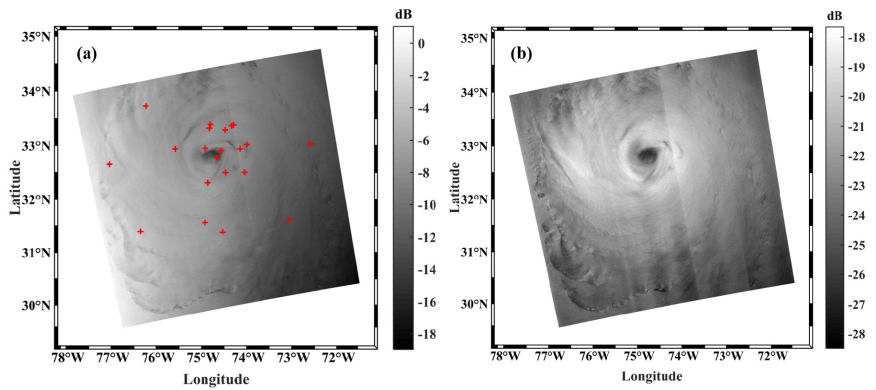

Fig. 14. RADARSAT-2 dual-polarization SAR image acquired over Hurricane Earl on September 2, 2010, at 22:59 UTC showing (a) VV-polarization and (b) VH-polarization, where the color bar shows $\sigma_{0}$ (dB) in VV-polarization $\left(\sigma_{\mathrm{VV}}^{0}\right)$ and in VH-polarization $\left(\sigma_{\mathrm{VH}}^{0}\right)$, respectively. The "red plus" represents the locations of dropsonde after adjustment. RADARSAT-2 Data and Product MacDonald, Dettwiler, and Associates Ltd., All Rights Reserved.
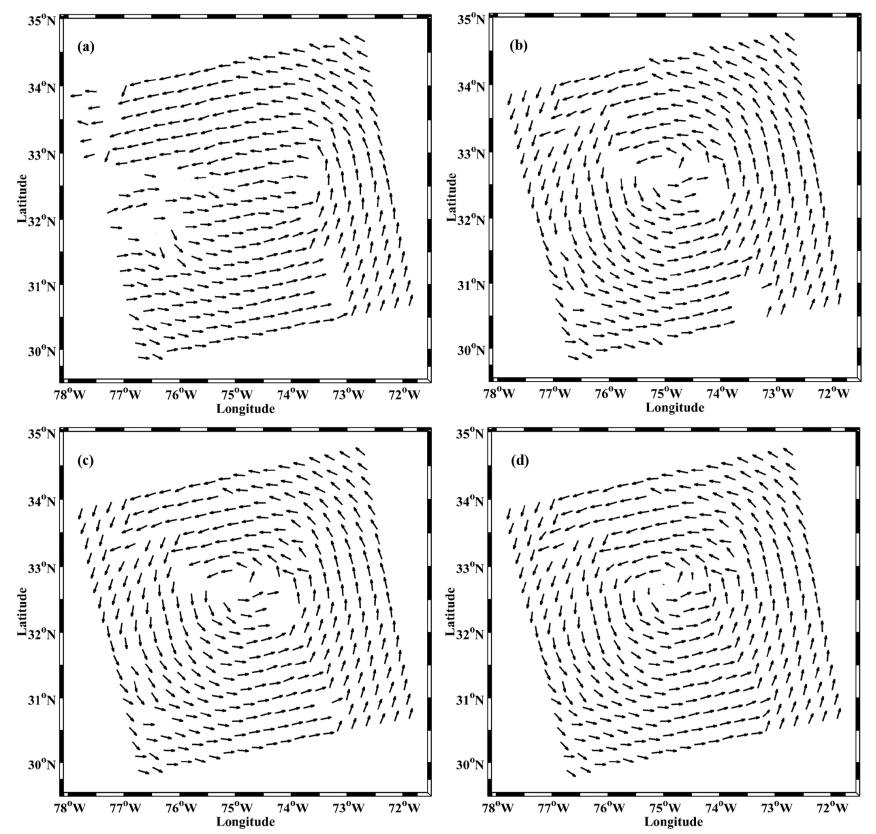

Fig. 15. SAR-retrieved wind directions of Hurricane Earl on September 2, 2010, at 22:59 UTC, with image of (a) VV-polarization, (b) VH-polarization, (c) dual-polarization (VV, VH), and (d) dual-polarization $(\mathrm{VV}+\mathrm{VH})$ and interpolation processing.

SAR, the bias and RMSE are $12.18^{\circ}$ and $28.22^{\circ}$; whereas for dual-polarized SAR, the bias and RMSE are $2.24^{\circ}$ and $26.05^{\circ}$.

In addition to the case-by-case validation for ten SAR images, we also perform a statistical comparison between SAR-retrieved wind directions and those measured from buoy, dropsonde, radiometer, and scatterometer data. The total number of collocated data pairs is 756. As shown in Fig. 17, wind directions from VV-polarized SAR have a bias of $-0.54^{\circ}$ and an RMSE of $14.78^{\circ}$; for VH-polarized SAR, the bias and RMSE are $0.38^{\circ}$ and $14.25^{\circ}$; whereas for dual-polarized SAR, the bias and RMSE are $0.2^{\circ}$ and $13.30^{\circ}$. Both the case study and the statistical results show that dual-polarization is always better than $\mathrm{VV}$ or $\mathrm{VH}$ for the retrieval of $\mathrm{TC}$ wind directions. In the future, we plan to conduct more TC wind direction validation studies, when additional reliable
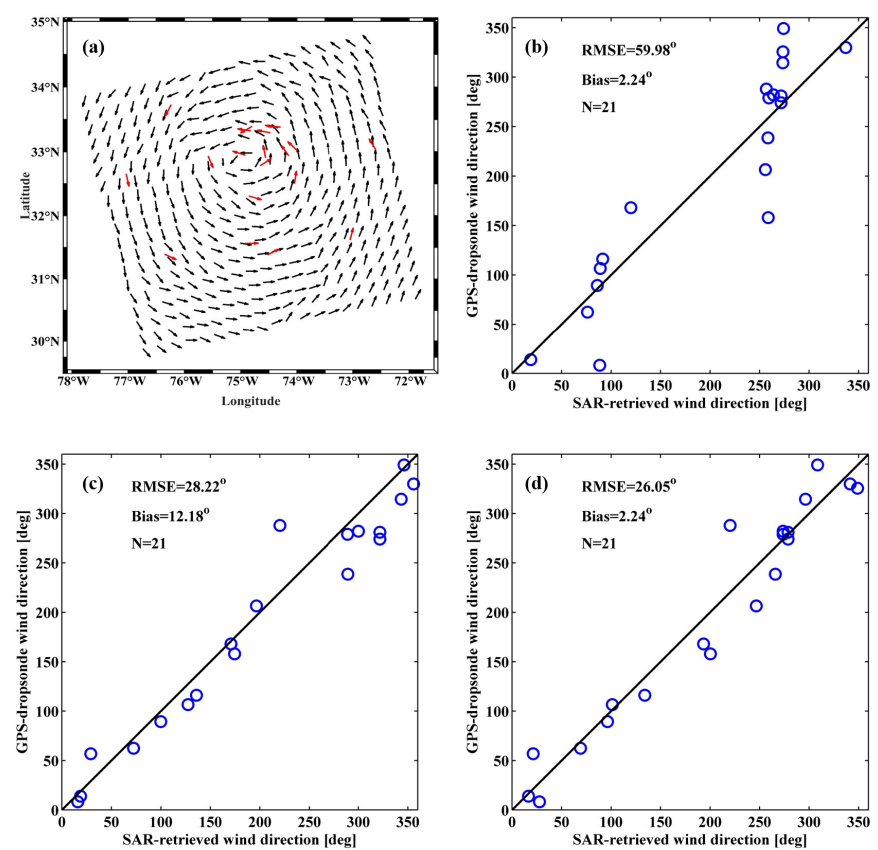

Fig. 16. (a) Dual-polarization SAR-retrieved wind directions of Hurricane Earl on September 2, 2010, at 22:59 UTC. (b) VV-polarization SAR-retrieved wind directions versus dropsonde-measured wind directions. (c) VH-polarization SAR-retrieved wind directions versus dropsondemeasured wind directions. (d) Dual-polarization (VV + VH) SAR-retrieved wind directions versus dropsonde-measured wind directions. The red arrows represent the wind directions measured by dropsondes.
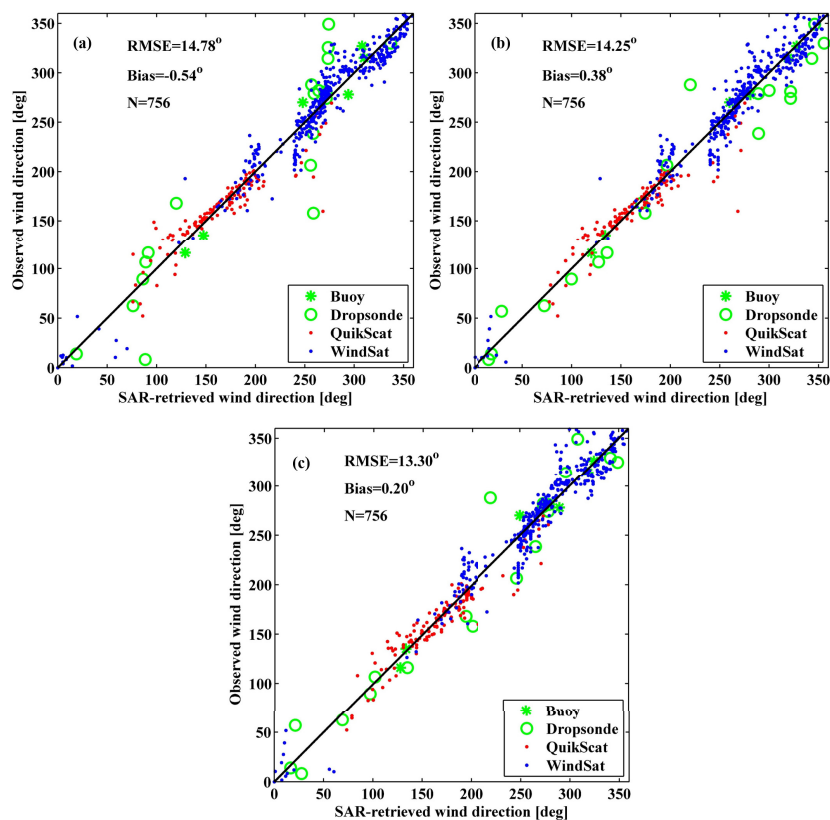

Fig. 17. (a) VV-polarization SAR-retrieved wind directions versus wind directions from buoy, dropsonde, QuikSCAT, and WindSat. (b) VH-polarization SAR-retrieved wind directions versus wind directions from buoy, dropsonde, QuikSCAT, and WindSat. (c) Dual-polarization SAR-retrieved wind directions versus wind directions from buoy, dropsonde, QuikSCAT, and WindSat.

measurements become available. There are several important factors that affect the VV- and VH-polarized SAR wind direction retrieval accuracy. The NESZ impact on the NRCS is 
one of these. There is also potential interchannel cross talk for dual-polarization data which cannot be corrected [46]. Investigations have demonstrated that the strongest wind regions within TCs are usually accompanied by significant rain [47]. Heavy rain contamination and additional effects associated with severe sea states can strongly dampen the VV- and VH-polarized NRCS [48]-[51] and, thus, affect the image gradient estimates for the wind direction retrieval. The wind direction retrieval error is also caused by the wind streak direction that is not fully parallel to the wind direction [52], [53]. However, the application of other parameters directly extracted from the SAR image, such as the geophysical Doppler contribution, may also lead to improvements in wind field retrievals. In particular, the geophysical signature in the Doppler contribution acquired in cross-polarization imagery over hurricanes remains to be documented, and its potential needs to be investigated.

\section{CONClusion}

The retrieval of the ocean surface wind fields from single-antenna SAR missions is an under-constrained inverse problem. The use of possibly inaccurate wind directions can lead to large errors in SAR wind speed retrievals. Estimating the wind direction directly from the SAR images is, thus, an attractive approach. Indeed, kilometer-scale wind streaks are frequently visible in SAR images due to MABL rolls, especially in TC conditions. For high winds, clear image contrasts (gradients) can be found in cross-polarized TC SAR images. Such gradients provide a good opportunity to derive wind directions using SAR images acquired in cross-polarization channel and possibly combined them with those derived from the co-polarized channel.

We applied the LG method to retrieve TC wind directions by using both VV- and VH-polarized SAR imagery. The spatial resolution of SAR-derived wind directions is $25 \mathrm{~km}$. Our analysis reveals that, as implemented, the LG method is dependent on the incidence angle in VV-polarization data and is more accurate for low to medium wind speed regimes. By comparison, VH-polarization does not seem sensitive to incidence angles but is more reliable for the strongest wind speeds. The SAR-retrieved wind directions have been quantitatively compared to data from collocated buoys, dropsonde, radiometer, and scatterometer estimates. Statistical comparisons of results show that the wind direction bias and RMSE are $-0.54^{\circ}$ and $14.78^{\circ}$, respectively, for VV-polarization, $0.38^{\circ}$ and $14.25^{\circ}$, respectively, for $\mathrm{VH}$-polarization, and $0.2^{\circ}$ and $13.30^{\circ}$, respectively, for dual-polarization. This suggests that SAR images acquired in dual-polarization are better than those in either VV- or VH-polarization to derive wind directions in storms. There are several causes for differences between wind direction estimates from SAR retrievals and collocated wind measurement data, including: 1) NESZ impact on NRCS; 2) potential cross talk between VV and VH channels; (3) the same mean inflow angle for different storms; and (4) the directions of wind streaks are not parallel to the wind directions.

In this study, no manual intervention was required for wind direction retrieval. Moreover, we automatically removed the $180^{\circ}$ ambiguity using characteristics of the expected TC wind direction structure. However, the validation of SAR-derived wind direction in storms is still a challenging problem because too few SAR TC images can be collocated with data from buoy, dropsonde, radiometer, and scatterometer measurements. It is, thus, necessary to collect more SAR imagery and auxiliary data to assess the LG method for wind direction retrieval under storm conditions.

\section{ACKNOWLEDGMENT}

The authors would like to thank the European Space Agency, Paris, France, for providing Sentinel-1A data and the Canadian Space Agency, Longueuil, QC, Canada, for providing the RADARSAT-2 data. They would like to thank the two anonymous reviewers for their constructive suggestions that greatly improve this article. They would also like to thank ESA Dragon project support. The National Oceanic and Atmospheric Administration (NOAA) buoy data are downloaded from http://www.ndbc.noaa.gov/.

\section{REFERENCES}

[1] K. B. Katsaros, P. W. Vachon, W. T. Liu, and P. G. Black, "Microwave remote sensing of tropical cyclones from space," J. Oceanogr., vol. 58, no. 1, pp. 137-151, 2002.

[2] J. Horstmann, D. R. Thompson, F. Monaldo, S. Iris, and H. C. Graber, "Can synthetic aperture radars be used to estimate hurricane force winds?" Geophys. Res. Lett., vol. 32, no. 22, p. L22801, 2005. doi: 10.1029/2005GL023992.

[3] H. Shen, W. Perrie, and Y. He, "A new hurricane wind retrieval algorithm for SAR images," Geophys. Res. Lett., vol. 33, no. 21, p. L21812, 2006. doi: 10.1029/2006GL027087.

[4] B. Zhang and W. Perrie, "Cross-polarized synthetic aperture radar: A new potential measurement technique for hurricanes," Bull. Amer. Meteorol. Soc., vol. 93, pp. 531-541, Apr. 2012. doi: 10.1175/BAMSD-11-00001.1.

[5] B. Zhang, W. Perrie, J. A. Zhang, E. W. Uhlhorn, and Y. He, "Highresolution hurricane vector winds from C-band dual-polarization SAR observations," J. Atmos. Ocean. Technol., vol. 31, no. 2, pp. 272-286, 2014. doi: 10.1175/JTECH-D-13-00006.1

[6] G. Zhang, X. Li, W. Perrie, P. A. Hwang, B. Zhang, and X. Yang, "A hurricane wind speed retrieval model for C-band RADARSAT2 cross-polarization ScanSAR images," IEEE Trans. Geosci. Remote Sens., vol. 55, no. 8, pp. 4744-4766, Aug. 2017.

[7] A. Mouche, B. Chapron, B. Zhang, and R. Husson, "Combined co- and cross-polarized SAR measurements under extreme wind conditions," IEEE Trans. Geosci. Remote Sens., vol. 55, no. 12, pp. 6746-6755, Dec. 2017.

[8] F. M. Monaldo, D. R. Thompson, R. C. Beal, W. G. Pichel, and P. Clemente-Colon, "Comparison of SAR-derived wind speed with model predictions and ocean buoy measurements," IEEE Trans. Geosci. Remote Sens., vol. 39, no. 12, pp. 2587-2600, Dec. 2001.

[9] T. Shimada, H. Kawamura, and M. Shimada, "An L-band geophysical model function for SAR wind retrieval using JERS-1 SAR," IEEE Trans. Geosci. Remote Sens., vol. 41, no. 3, pp. 518-531, Mar. 2003.

[10] T. W. Gerling, "Structure of the surface wind field from the Seasat SAR," J. Geophys. Res., Oceans, vol. 91, no. C2, pp. 2308-2320, Feb. 1986.

[11] W. Alpers and B. Brümmer, "Atmospheric boundary layer rolls observed by the synthetic aperture radar aboard the ERS-1 satellite," J. Geophys. Res., vol. 99, no. C6, pp. 12613-12621, 1994.

[12] P. W. Vachon and F. W. Dobson, "Validation of wind vector retrieval from ERS-1 SAR images over the ocean," Global Atmos. Ocean Syst., vol. 5, no. 2, pp. 177-187, 1996.

[13] S. Lehner, J. Horstmann, W. Koch, and W. Rosenthal, "Mesoscale wind measurements using recalibrated ERS SAR images," J. Geophys. Res., Oceans, vol. 103, no. C4, pp. 7847-7856, Apr. 1998.

[14] F. Fetterer, D. Gineris, and C. C. Wackerman, "Validating a scatterometer wind algorithm for ERS-1 SAR," IEEE Trans. Geosci. Remote Sens., vol. 36, no. 2, pp. 479-492, Mar. 1998. 
[15] W. Koch, "Directional analysis of SAR images aiming at wind direction," IEEE Trans. Geosci. Remote Sens., vol. 42, no. 4, pp. 702-710, Apr. 2004.

[16] J. Horstmann, W. Koch, S. Lehner, and R. Tonboe, "Ocean winds from RADARSAT-1 ScanSAR," Can. J. Remote Sens., vol. 28, no. 3, pp. 524-533, 2002.

[17] Y. Du, P. W. Vachon, and J. Wolfe, "Wind direction estimation from SAR images of the ocean using wavelet analysis," Can. J. Remote Sens., vol. 28, no. 3, pp. 498-509, 2002.

[18] G. Levy and R. A. Brown, "Detecting planetary boundary layer rolls from SAR," in Remote Sensing of the Pacific Ocean From Satellite, R. A. Brown, Ed. Eveleigh, NSW, Australia: Earth Ocean and Space, 1998, pp. 128-134.

[19] Y. Zhao, X.-M. Li, and J. Sha, "Sea surface wind streaks in spaceborne synthetic aperture radar imagery," J. Geophys. Res., vol. 121, no. 9, pp. 6731-6741, 2016.

[20] R. C. Foster, "Why rolls are prevalent in the hurricane boundary layer," J. Atmos. Sci., vol. 62, pp. 2647-2661, Aug. 2005.

[21] L. Huang et al., "Tropical cyclone boundary layer rolls in synthetic aperture radar," J. Geophys. Res., vol. 123, no. 4, pp. 2981-2996, Apr. 2018. doi: 10.1029/2018JC013755.

[22] J. A. Zhang, K. B. Katsaros, P. G. Black, S. Lehner, J. R. French, and W. M. Drennan, "Effects of roll vortices on turbulent fluxes in the hurricane boundary layer," Bound.-Layer Meteorol., vol. 128, no. 2, pp. 173-189, 2008.

[23] X. Li et al., "Tropical cyclone morphology from spaceborne synthetic aperture radar," Bull. Amer. Meteorol. Soc., vol. 94, no. 2, pp. 215-230, Feb. 2013.

[24] A. Reppucci, S. Lehner, J. Schulz-Stellenfleth, and S. Brusch, "Tropical cyclone intensity estimated from wide-swath SAR images," IEEE Trans. Geosci. Remote Sens., vol. 48, no. 4, pp. 1639-1649, Apr. 2010.

[25] Y. Zhao, A. A. Mouche, B. Chapron, and N. Reul, "Direct comparison between active C-band radar and passive L-band radiometer measurements: Extreme event cases," IEEE Geosci. Remote Sens Lett., vol. 15, no. 6, pp. 897-901, Jun. 2018.

[26] A. A. Mouche et al., "On the use of Doppler shift for sea surface wind retrieval from SAR," IEEE Trans. Geosci. Remote Sens., vol. 50, no. 7, pp. 2901-2909, Jul. 2012.

[27] B. Slade, RADARSAT-2 Product Description, document RN-SP-52-1238, MacDonald, Detwiler and Associates Ltd., 2009, p. 46. [Online]. Available: http://gs.mdacorporation.com/products/ sensor/radarsat2/RS2_Product_Description.pdf

[28] A. Mouche and B. Chapron, "Global C-band ENVISAT, RADARSAT2 and Sentinel-1 SAR measurements in copolarization and crosspolarization," J. Geophys. Res., vol. 120, pp. 7195-7207, 2015.

[29] R. Dunbar and K. L. Perry, JPL SeaWinds Project. (2001). SeaWinds on QuikSCAT Level 3 Daily, Gridded Ocean Wind Vectors. [Online]. Available: ftp://podaac-ftp.jpl.nasa.gov/allData/ quikscat/L3/jpl/docs/qscat_L3.pdf

[30] P. S. Callahan, QuikSCAT Science Data Product User'S Manual: Overview and Geophysical Data Products, Version 3.0., document JPL D-18053-RevA, 2006.

[31] L. Ricciardulli and F. J. Wentz, "A scatterometer geophysical model function for climate-quality winds: QuikSCAT Ku-2011," J. Atmos. Ocean. Technol., vol. 32, no. 10, pp. 1829-1846, Oct. 2015.

[32] L. Ricciardulli and F. J. Wentz, "Reprocessed QuikSCAT (V04) wind vectors with ku-2011 geophysical model function," Remote Sens. Syst., Santa Rosa, CA, USA, Tech. Rep., 2011.

[33] P. W. Gaiser et al., "The WindSat spaceborne polarimetric microwave radiometer: Sensor description and early orbit performance," IEEE Trans. Geosci. Remote Sens., vol. 42, no. 11, pp. 2347-2361, Nov. 2004.

[34] T. Meissner and F. J. Wentz, "Wind-vector retrievals under rain with passive satellite microwave radiometers," IEEE Trans. Geosci. Remote Sens., vol. 47, no. 9, pp. 3065-3083, Sep. 2009.

[35] T. F. Hock and J. L. Franklin, "The NCAR GPS dropwindsonde," Bull. Amer. Meteorol. Soc., vol. 80, pp. 407-420, Mar. 1999.

[36] J. L. Franklin, M. L. Black, and K. Valde, "GPS dropwindsonde wind profiles in hurricanes and their operational implications," Weather Forecasting, vol. 18, no. 2, pp. 32-44, Mar. 2003.

[37] J. Wang, "A long-term, high-quality, high-vertical-resolution GPS dropsonde dataset for hurricane and other studies," Bull. Amer. Meteorol. Soc., vol. 96, pp. 961-973, Jun. 2015. doi: 10.1175/BAMS-D-1300203.1.

[38] J. A. Zhang, R. Atlas, G. D. Emmitt, L. Bucci, and K. Ryan, "Airborne Doppler wind lidar observations of the tropical cyclone boundary layer," Remote Sens., vol. 10, no. 6, p. 825, 2018. doi: $10.3390 /$ rs 10060825
[39] K.-H. Chou, C.-C. Wu, P.-H. Lin, and S. Majumdar, "Validation of QuikSCAT wind vectors by dropwindsonde data from dropwindsonde observations for typhoon surveillance near the taiwan region (DOTSTAR)," J. Geophys. Res., vol. 115, no. D2, p. 02109, 2010. doi: 10.1029/2009jd012131.

[40] R. C. Gonzalez and R. E Woods, Digital Image Processing, 3rd ed. Upper Saddle River, NJ, USA: Prentice-Hall, Inc. 2007.

[41] D. J. Shea and W. M. Gray, "The hurricane's inner core region. I. Symmetric and asymmetric structure," J. Atmos. Sci., vol. 30, no. 8, pp. 1544-1564, 1973.

[42] J. Zhang and E. W. Uhlhorn, "Hurricane sea surface inflow angle and an observation-based parametric model," Monthly Weather Rev., vol. 140, pp. 3587-3605, Nov. 2012.

[43] H. Scharr, "Optimal operators in digital image processing," Ph.D. dissertation, Dept. Interdiscipl. Center Sci. Comput., Univ. Heidelberg, Heidelberg, Germany, 2000.

[44] A. A. Mouche, B. Chapron, and N. Reul, "A simplified asymptotic theory for ocean surface electromagnetic wave scattering," Waves Random Complex Media, vol. 17, no. 3, pp. 321-341, 2007.

[45] G. Zhang, B. Zhang, W. Perrie, Q. Xu, and Y. He, "A hurricane tangential wind profile estimation method for C-band crosspolarization SAR," IEEE Trans. Geosci. Remote Sens., vol. 52, no. 11, pp. 7186-7194, Apr. 2014.

[46] R. Touzi, P. W. Vachon, and J. Wolfe, "Requirement on antenna cross-polarization isolation for the operational use of C-band SAR constellations in maritime surveillance," IEEE Geosci. Remote Sens. Lett., vol. 7, no. 4, pp. 861-865, Oct. 2010.

[47] D. E. Weissman and M. A. Bourassa, "The influence of rainfal on scatterometer backscatter within tropical cyclone environmentsImplications on parameterization of sea-surface stress," IEEE Trans. Geosci. Remote Sen., vol. 49, no. pp. 4805-4814, Dec. 2011.

[48] A. Reppucci "Extreme wind conditions observed by satellite synthetic aperture radar in the North West Pacific," Int. J. Remote Sens., vol. 29, no. 21, pp. 6129-6144, 2008.

[49] G. Zhang, X. Li, W. Perrie, B. Zhang, and L. Wang, "Rain effects on the hurricane observations over the ocean by C-band synthetic aperture radar," J. Geophys. Res., vol. 120, no. 1, pp. 14-26, Jan. 2016. doi: 10.1002/2015JC011044.

[50] W. Alpers, B. Zhang, A. Mouche, K. Zeng, and P. W. Chan, "Rain footprints on C-band synthetic aperture radar images of the oceanRevisited," Remote Sens. Environ., vol. 187, pp. 169-185, Dec. 2016.

[51] B. Zhang and W. Alpers, "The effect of rain on radar backscattering from the ocean," in Advances in SAR Remote Sensing of Oceans. Boca Raton, FL, USA: CRC Press, 2018, pp. 317-330.

[52] I. Morrison, S. Businger, F. Marks, P. Dodge, and J. A. Businger, "An observational case for the prevalence of roll vortices in the hurricane boundary layer," J. Atmos. Sci., vol. 62, no. 8, pp. 2662-2673, Aug. 2005.

[53] S. Lorsolo, J. L. Schroeder, P. Dodge, and F. Marks, "An observational study of hurricane boundary layer small-scale coherent structures," Monthly Weather Rev., vol. 136, pp. 2871-2893, Aug. 2008.

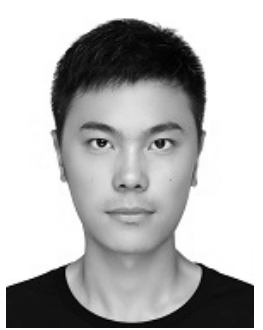

Shengren Fan received the B.S. degree in atmosphere sciences and the M.S. degree in marine meteorology from the Nanjing University of Information Science and Technology, Nanjing, China, in 2016 and 2019, respectively, where he is currently pursuing the $\mathrm{Ph}$.D. degree in marine meteorology.

His research interests include microwave scattering numerical simulation and tropical cyclone remote sensing through dual-polarization synthetic aperture radar. 


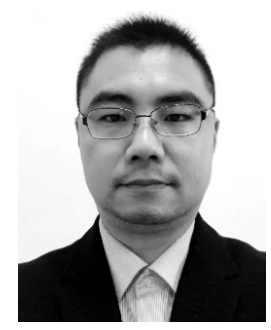

Biao Zhang (M'08-SM'16) received the B.S. degree in surveying and mapping engineering from the China University of Petroleum, Dongying, China, in 2003, and the Ph.D. degree in physical oceanography from the Institute of Oceanology, Chinese Academy of Sciences, Qingdao, China, in 2008 .

From 2008 to 2011, he was a Post-Doctoral Fellow with the Canadian Government Laboratory, Bedford Institute of Oceanography, Dartmouth, NS, Canada. In 2011, he joined the School of Marine Sciences, Nanjing University of Information Science and Technology, Nanjing, China, as a Professor. In 2015, he joined the Department of Mechanical Engineering, University of Maryland, College Park, MD, USA, as a Visiting Scientist. His research interests include ocean surface waves and wind fields remote sensing by along-track interferometric, multipolarization, and compact polarimetric synthetic aperture radar (SAR), marine weather events such as typhoons or hurricanes monitoring with active SAR and passive radiometer observations, mesoscale eddy and cellular convection studies, spaceborne multisensor study of sea surface thermal fronts, and air-sea interaction investigation using remote sensing and numerical models.

Dr. Zhang was a recipient of the Visiting Fellow Scholarship of Natural Sciences and Engineering Research Council of Canada, the Outstanding Young Scientist Award by the National Science Foundation of China in 2016 , the First Award of Science and Technology from Jiangsu Province in 2017, the First Award of Ocean Science and Technology from the State Oceanic Administration of China, and the Second Award of Natural Science from the Ministry of Education of China in 2014.

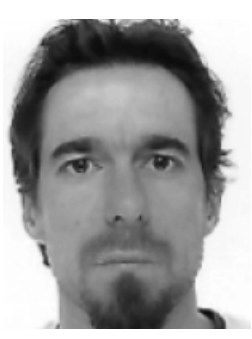

Alexis A. Mouche received the Ph.D. degree in ocean remote sensing from the Université de Versailles Saint-Quentin, Versailles, France, in 2005 .

He has been a Senior Research Scientist with the Laboratoire d'Océanographie Physique et Spatiale, Institut Francais de Recherche pour l'Exploitation de la Mer, Plouzané, France, since 2014. His research interests include the interaction of electromagnetic and oceanic waves for ocean remote sensing applications.

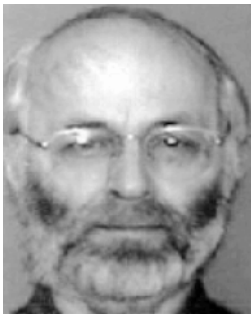

William Perrie received the B.S. degree in physics from the University of Toronto, Toronto, ON, Canada, in 1973, and the Ph.D. degree in meteorology and oceanography from the Massachusetts Institute of Technology, Cambridge, MA, USA, in 1979.

He was a Post-Doctoral Fellow of oceanography and mathematics with the University of British Columbia, Vancouver, BC, Canada, and the National Center for Atmospheric Research, Boulder, CO, USA. He is currently a Senior Scientist with the Bedford Institute of Oceanography, Dartmouth, NS, Canada, and an Adjunct Professor with Dalhousie University, Halifax, NS His research interests include the modeling of ocean waves, air-sea fluxes, coupled atmosphere-ocean interactions and impacts of climate change on these variables, and field measurements via remote sensing and in situ of winds, waves, and currents.

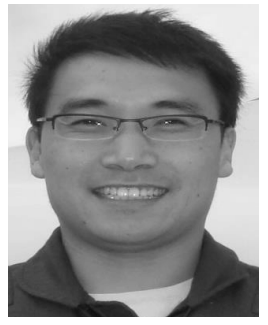

Jun A. Zhang (M'00-SM'11) received the B.S. degree in naval architecture and ocean engineering from the Dalian University of Technology, Dalian, China, in 2000, and the M.S. and Ph.D. degrees in applied marine physics from the Rosenstiel School of Marine and Atmospheric Science, University of Miami, Miami, FL, USA, in 2005 and 2007, respectively.

Since 2008, he has been with the National Oceanic and Atmospheric Administration (NOAA)/Atlantic Oceanographic and Meteorological Laboratory/ Hurricane Research Division (HRD), Miami. He is involved in hurricane field experiments with HRD. He is also involved in improving hurricane model physics using aircraft data. He has authored more than 40 peerreviewed publications. His research interests include boundary layer structure and dynamics, turbulence, air-sea interaction, remote sensing, numerical modeling, and physical parameterizations.

Dr. Zhang has been serving as an Associate Editor for Monthly Weather Review since 2013.

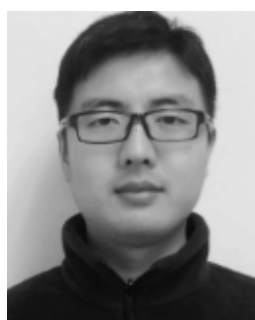

Guosheng Zhang received the B.S. degree in marine management from the Ocean University of China, Qingdao, China, in 2009, and the Ph.D. degree in physical oceanography from Hohai University, Nanjing, China, in 2014.

Since 2015, he has been a Post-Doctoral Fellow with Fisheries and Oceans Canada, Bedford Institute of Oceanography, Dartmouth, NS, Canada. In 2018, he joined the School of Marine Sciences, Nanjing University of Information Science and Technology, Nanjing, as a Professor. His research interests include ocean wind measured by the microwave radar remote sensing, especially hurricanes imaged by synthetic aperture radar (SAR) over the ocean surface 